\title{
OBJECTIVE EVALUATION OF UPPER LIMB CLAUDICATION: USE OF ISOKINETIC DYNAMOMETRY
}

Lívio Nakano, Nelson Wolosker, Ruben Ayzin Rosoki, Baptista Muraco Netto, and Pedro Puech-Leão

\begin{abstract}
Nakano L, Wolosker N, Rosoki RA, Muraco Netto B, Puech-Leão P. Objective evaluation of upper limb claudication: use of isokinetic dynamometry. Clinics. 2006;61(3):189-96.
\end{abstract}

OBJECTIVE: The objective of this work is to present an objective, practical, and reproducible method for evaluating the functional limitation caused by occlusive arterial disease in upper limbs: a stress test using an isokinetic dynamometer.

METHODS: Twenty-three patients with unilateral subclavian artery occlusive disease were included in the study, forming group 1. Seven patients of similar age, with atherosclerotic or Takayasu's disease in the aorto-iliac segment, without subclavian artery occlusive disease, were included as a control group (group 2). For all tests, we utilized the CYBEX® 6000 isokinetic dynamometer. The elbow was tested using a series of 30 repetitions of extension and flexion of the arm, performed up to a maximum of 270 repetitions (9 series) or until the limit of the tested limb was reached.

RESULTS: We initially compared all the limbs without arterial disease of both groups to analyze whether they presented similar functional performance. No significant difference was found for any of the parameters studied. Considering that upper limbs without arterial disease have a similar response to exercise in these analyzed parameters, we compared the upper limbs in group 1 (with and without subclavian artery occlusive disease). For all parameters, the limbs with subclavian artery occlusive disease presented significantly lower values than the control limbs $(P<0.05)$, which can be objectively attributed to the ischemia (there were different responses in different individuals, which allows the quantification of the limitation caused by subclavian artery occlusive disease).

CONCLUSION: In this study, we present a new stress test for impairment in patients with subclavian artery occlusive disease that might facilitate the classification of patients according to their functional impairment, and thus result in a better choice of therapeutic approach for each case as well as reporting of objective parameters that allow comparisons of the results of different treatments, including for long-term follow-up.

KEYWORDS: Ischemia. Upper extremity/blood supply. Exercise test/instrumentation. Intermittent claudication. Blood pressure. Subclavian steal syndrome.

\section{INTRODUCTION}

With the evolution of diagnosis and intervention techniques, increasing numbers of patients with occlusions in supra-aortic trunk arteries have been identified. The numbers of procedures that such patients undergo have also

Department of Vascular Surgery, São Paulo University Medical School São Paulo/SP, Brazil.

Email: livio.nakano@gmail.com

Received for publication on January 01, 2006.

Accepted for publication on March 17, 2006. been increasing. ${ }^{1,2,3}$

The clinical status of subclavian artery occlusive disease (SAOD) varies according to the degree of stenosis/occlusion $^{4,5,6}$ and the quantity of collateral circulation. ${ }^{7,8,9,10}$ The presence of trophic lesions or ischemic pain is uncommon, but claudication of the upper limbs occurs with notable frequency. ${ }^{11}$

The diagnosis of occlusive disease in subclavian arteries is based on the patient's history, physical examination, imaging examinations ${ }^{12}$ (Duplex scan, arteriography, and angioresonance), and physiological examinations, such as 
measurements of segmental pressure differences, Dopplercalibrated pulse wave, and plethysmography. ${ }^{13,14,15}$

Although these tests are well established, the functional limitation caused by SAOD still cannot be objectively measured, and it continues to be subjectively estimated on the basis of the patient's history, from the patient's perception of his own physical limitations. Hence, it has not been possible to objectively evaluate the results from the various types of treatments available nowadays. This is a very important clinical problem.

The isokinetic dynamometer is today one of the more precise available methods for analysis of muscular performance. ${ }^{16}$ The objective of this work was to present an objective, practical, and reproducible method for evaluating the functional limitation caused by SAOD: ie, a stress test for upper limbs using an isokinetic dynamometer.

\section{SAMPLE}

Twenty-three patients with unilateral SAOD were included in the study, forming group 1. Seven patients of similar age, with atherosclerotic or Takayasu's disease in the aortoiliac segment but without SAOD, were included as a control group (group 2). We selected the control group patients so as to match the group 1 patients with regard to sex, age, risk factors, and their sedentary lifestyles.

All the patients in group 1 were followed up regularly for at least 6 months, and they presented stable symptoms at the time of the test. All these patients were questioned about their symptoms; these ranged from mild and nonspecific symptoms to significant limitations on performing any daily activities (Table 1). Their ages ranged from 19 to 70 years (average of 50.6 years), and 17 patients were women $(74 \%)$. Takayasu disease occurred in 14 patients, and atherosclerosis occurred in the other 9 (Table 2). The left limb (nondominant) was affected in 17 patients, and the right (dominant) was affected in 6 cases. The diagnosis and location of the arterial disease in group 1 were confirmed by arteriography or magnetic angioresonance.

Patients were not included in the study if they presented the following: an orthopedic disease or condition in the upper limbs that limited their physical performance; neurological disease that interfered with the perception of pain or led to motor deficiency or deformity of the upper limbs; active inflammatory disease progressing with limitation of mobilization or movement amplitude; or finally, functional limitation of physical activity for reasons other than SAOD, namely, acute myocardial infarct or angina, congestive heart failure of NYHA Class III (shortness of breath upon less-than-ordinary exertion), or states of dementia. Nor were patients with bilateral SAOD included.
Table 1 - Functional limitation imposed by patients' symptoms

\begin{tabular}{lccc}
\hline Number & Symptomatic side & Dominance & Symptoms \\
\hline 1 & left & right & Grade 2 \\
2 & right & right & Grade 3 \\
3 & left & right & Grade 2 \\
4 & left & right & Grade 2 \\
5 & left & right & Grade 2 \\
6 & left & right & Grade 1 \\
7 & left & right & Grade 1 \\
8 & right & right & Grade 1 \\
9 & left & right & Grade 1 \\
10 & right & right & Grade 2 \\
11 & left & right & Grade 1 \\
12 & left & right & Grade 2 \\
13 & left & right & Grade 2 \\
14 & left & right & Grade 1 \\
15 & right & right & Grade 2 \\
16 & right & right & Grade 1 \\
17 & right & right & Grade 2 \\
18 & left & right & Grade 1 \\
19 & left & right & Grade 1 \\
20 & left & right & Grade 3 \\
21 & left & right & Grade 2 \\
22 & left & right & Grade 1 \\
23 & left & right & Grade 2 \\
\hline
\end{tabular}

Grade 0: No limitation of physical activity (Ordinary physical activity does not cause symptoms)

Grade 1: Slight limitation of physical activity (Ordinary physical activity does cause symptoms)

Grade 2: Moderate limitation of activity (Patient is comfortable at rest, but less than ordinary activities cause symptoms)

Grade 3: Unable to perform any physical activity without discomfort, therefore severe limitation

The patients in group 2 were selected from among patients with atherosclerosis or Takayasu's disease but without SAOD who were attended at the vascular surgery outpatient service. Their ages ranged from 24 to 68 years (average of 53 years), and there were 5 women. The absence of vascular lesions in the upper limbs was confirmed by physical examination, segmental pressure measurements, and Duplex scan.

Segmental pressure was recorded in both upper limbs for all patients. Those in group 1 presented a systolic arterial pressure gradient between their arms of at least $20 \mathrm{~mm}$ $\mathrm{Hg}$. The patients in group 2 did not present pressure differences between their arms of more than $10 \mathrm{~mm} \mathrm{Hg}$.

\section{METHOD}

All patients underwent the isokinetic test using a CYBEX $^{\hat{a}} 6000$ isokinetic dynamometer (Cybex Division of Lumex, Inc., 2100 Smithtown Ave, Ronkonkoma, NY 11779). All tests were monitored personally by the researchers. All patients received continuous cardiac monitoring via cardioscopy, and 2 measurements of systolic blood pressure 
using a Doppler ultrassound were made in the tested limb immediately before and after the test, in order to observe all possible changes caused by the stress test.

The patients were positioned on a chair that forms part of the equipment (UBXT module). The chest was secured to the bench, the contralateral limb was supported on a bar, and the arm to be tested was secured to the chest, so that interference from the trunk and shoulder musculature would be avoided during the test. The axis of movement was set up in the elbow immediately distal to the lateral epicondyle (Figure 1).

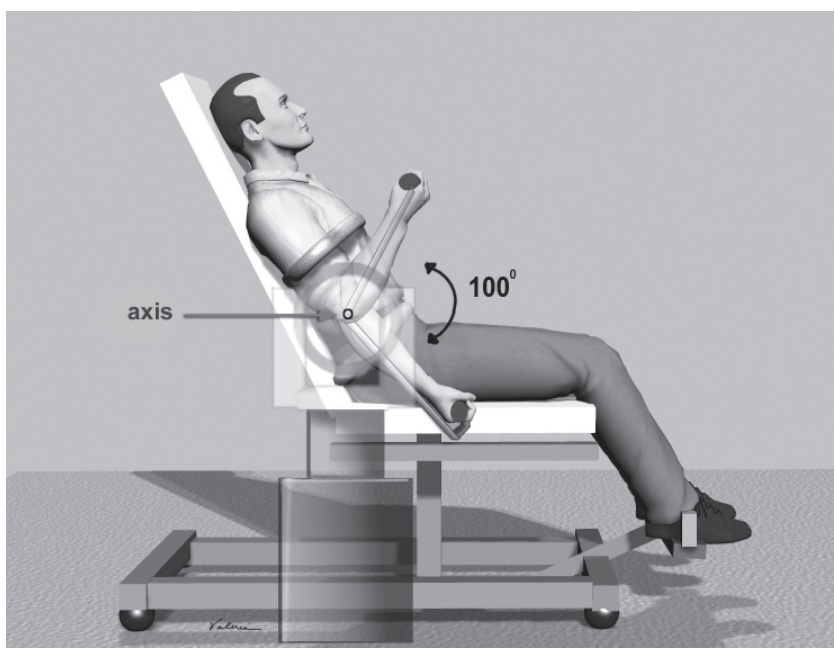

Figure 1 - Position of the patient

The elbow was tested using flexion/extension movement at an angular velocity of $180^{\circ}$ per second. For this, an adaptation of the elbow flexion/extension protocol (DAP0115) recommended by the equipment manufacturer was utilized (equipment manual).

The amplitude of the flexion/extension movement was established across the range from zero (total extension) to $100^{\circ}$ (total flexion), considering anatomical zero to be the extension of the elbow (Figure 1). Several series of 30 repetitions of the flexion/extension movement were performed with an interval of 5 seconds between each one, up to a maximum of 270 repetitions ( 9 series).

The patients underwent the test without any restriction on eating before the test. They only needed to observe that they were to avoid extensive physical activity using the upper limbs during the 48 hours preceding the examination.

Before the test, patients were advised to concentrate only on their task, attempting to achieve as many repetitions as possible until the pain triggered by the exercise impeded them from continuing with the test. Patients were also requested to indicate the exact moment when pain began.

For the patients in group 1, the first limb tested was the one without arterial disease, while for the patients in group 2 , it was the dominant arm. This was followed by a period of rest until the heart rate, arterial pressure, and breathing rate returned to the levels measured before the test, and until the patient was ready to do the test on the other arm. At that time, the contralateral limb was also submitted to the standardized stress test.

All patients who interrupted the test before reaching 270 repetitions had to do so because of pain in the arm muscles that limited their test performance. Although all the patients presented occlusion of the proximal section of the subclavian artery before the emergence of the vertebral artery, no patient presented symptoms of subclavian steal syndrome, incapacitating dyspnea, or chest pain triggered by the test.

The following variables were studied: maximum number of repetitions; systolic arterial pressure before and immediately after the end of the exercise; heart rate monitored throughout the test and recorded after every 5 repetitions; measurements of muscle performance gauged by the isokinetic dynamometer; and maximum torque and total work.

\section{STATISTICAL ANALYSIS}

Initially, the parameters for the limb without SAOD of group 1 were compared with those of group 2 (control). Student's $t$ test for independent samples was used for studying the systolic arterial pressure (normal distribution). Other variables with nonparametric distribution (maximum number of repetitions, total work, and maximum torque) were analyzed using the Mann-Whitney test for independent samples.

Similarly, the comparison between the limbs with and without SAOD among the patients in group 1 was done via Student's $t$ test for paired samples for the pressure variables and via the Wilcoxon test for other variables.

The significance level of $0.05(\alpha=5 \%)$ was adopted, and probability levels $(P)$ that were lower than this value were considered to be significant and were marked by an asterick (*).

\section{RESULTS}

Considering the variables defined by our protocol, we chose an angular velocity of 180 degrees per second, because this velocity is intermediate between a slow movement requiring great strength and a high velocity that requires sports reflex. Thus, the test could be performed by any individual without specific prior training. This velocity allowed a larger number of repetitions and more precise differentiation between the different degrees of func- 
tional limitation. Within this protocol, $68 \%$ of the limbs without SAOD accomplished the test to conclusion, with $86 \%$ achieving 210 or more repetitions. The diseased limbs attained varying proportions of the number of repetitions possible, thus allowing objective quantification of their limitation. Only $17 \%$ of the limbs with SAOD achieved the 270 repetitions proposed, and $65 \%$ of these limbs attained less than 210 repetitions. The movement amplitude of 100 degrees was chosen because this is the normal articulation amplitude within which the best biomechanical performance of muscle leverage by the flexors and extensors of the elbow takes place.

The dynamometer also registers muscular performance parameters that enable quantification of the limitation caused by SAOD according to the torque, ie, the force applied through the distance traversed. This was analyzed in terms of peak torque, ie, the maximum torque value obtained for each series of 30 repetitions and thus representing the best movement among all the repetitions. The work done by the movement was the product of the torque over the whole movement arc. This was analyzed as total work, ie, the sum of the work done through each movement.

We initially compared all the limbs without arterial disease in group 1 versus all the limbs in group 2 to evaluate whether they presented similar functional performance. No statistical difference was found between groups 1 and 2 regarding to the number of repetitions $(P=0.117)$, total work throughout the test $(P=0.604)$, average work per series of 30 repetitions $(P=0.916)$, average work per repetition ( $P=0.916)$, peak torque $(P=0.204)$, or the ratio between the systolic arterial pressure measurements $(P=0.449)$.

The only parameter that presented a significant difference between the two groups was the measurement of systolic arterial pressure before $(P=0.037)$ and after the test $(P=0.031)$, which was greater in group 1 (unilateral SAOD) than in group 2 (control).

Considering that the parameters analyzed showed that upper limbs without arterial disease had similar responses to exercise, we decided to make comparisons between the upper limbs of each patient in group 1 ( $P$ with and without SAOD). The parameters analyzed are shown in Table 3.

Significant differences were found between the two groups in relation to number of repetitions $(P<0.001)$; total work throughout the test $(P<0.001)$; average work per series of 30 repetitions $(P=0.022)$; average work per repetition $(P=0.022)$; peak torque $(P=0.019)$; systolic arterial pressure before the test $(P<0.001)$; systolic pressure after the test $(P<0.001)$; and the ratio between the systolic pressures $(P<0.001)$. For all these parameters, the limbs with SAOD presented significantly lower values than the limbs without SAOD.

The maximum number of repetitions was registered as a first estimate of the functional limitation of the member submitted to the test.

The differences in systolic arterial blood pressure were used as a first estimate of the degree of limitation to perfusion caused by the arterial obstruction and the changes caused by the test. Although these measurements were considered valuable, they are limited in many clinical situations. On the basis of previous experience with lower limbs, absolute Doppler measurements alone do not necessarily correlate with clinical limitations and are not raised when patients increase their maximum walking distance. ${ }^{17}$

\section{DISCUSSION}

Treadmill test protocols are being used in the objective evaluation of the functional limitations of lower limbs due to ischemia (intermittent claudication). ${ }^{18,19,20}$ Subjective parameters for estimating maximum walking distances are no longer used, and scientifically, they cannot be accepted anymore. When the ischemic functional limitation occurs in upper limbs, there is not a reliable method for objectively determining this limitation.

In 1986, Gerdle et al observed in lower limbs that measurements of work performed by patients with intermittent claudication that were obtained via an isokinetic dynamometer had a direct relationship with the maximum walking distance obtained in a treadmill test. ${ }^{21}$ Hedberg, in 1988, analyzed the results from the treatment of 2 groups of patients with intermittent claudication; the first group underwent surgical treatment with bypass surgery ( 8 patients), and the second group underwent clinical treatment with physical exercises ( 9 patients), with the parameters obtained from isokinetic dynamometer prior to and after the treatment compared. Both groups increased the maxi-

Table 2 - Subclavian artery occlusive disease group - Patients' characteristics

\begin{tabular}{|c|c|c|c|c|c|c|c|c|}
\hline \multirow[t]{2}{*}{ Etiology } & \multirow[t]{2}{*}{ Patients } & \multirow[t]{2}{*}{ Females } & \multirow[t]{2}{*}{ Males } & \multirow[t]{2}{*}{ Average age } & \multicolumn{4}{|c|}{ RISK FACTORS } \\
\hline & & & & & Hypertension & Smoking & Diabetes mellitus & Cholesterol \\
\hline Atherosclerosis & 9 & 5 & 4 & 60.12 & 7 & 6 & 2 & 5 \\
\hline Takayasu & 14 & 12 & 2 & 43.81 & 3 & 0 & 0 & 1 \\
\hline Total & 23 & 17 & 6 & 50.68 & 10 & 6 & 2 & 6 \\
\hline
\end{tabular}


Table 3 - Parameters analyzed comparing the ischemic and control limbs in Subclavian artery occlusive disease (SAOD) group

\begin{tabular}{|c|c|c|c|c|}
\hline \multirow[t]{2}{*}{ Parameter } & & \multicolumn{2}{|c|}{ Limbs in SAOD group } & \multirow[t]{2}{*}{$P$ value } \\
\hline & & $\begin{array}{l}\text { Ischemic limb } \\
\qquad(n=23)\end{array}$ & $\begin{array}{l}\text { Control limb } \\
(\mathrm{n}=23)\end{array}$ & \\
\hline Number of repetitions & $\begin{array}{l}\text { Average } \pm \text { SD } \\
\text { Median } \\
\text { Min. / Max. }\end{array}$ & $\begin{array}{c}147.39 \pm 85.28 \\
120 \\
60 / 270\end{array}$ & $\begin{array}{c}237.39 \pm 47.26 \\
270 \\
120 / 270\end{array}$ & $<0.001$ \\
\hline Systolic arterial pressure before the test $(\mathrm{mm} \mathrm{Hg})$ & $\begin{array}{c}\text { Average } \pm \text { SD } \\
\text { Median } \\
\text { Min. / Max. }\end{array}$ & $\begin{array}{c}102.83 \pm 19.70 \\
100 \\
80 / 150\end{array}$ & $\begin{array}{c}142.39 \pm 27.46 \\
140 \\
110 / 200\end{array}$ & $<0.001$ \\
\hline Systolic arterial pressure after the test ( $\mathrm{mm} \mathrm{Hg}$ ) & $\begin{array}{l}\text { Average } \pm \text { SD } \\
\text { Median } \\
\text { Min. / Max. }\end{array}$ & $\begin{array}{c}86.09 \pm 29.88 \\
90 \\
0 / 150\end{array}$ & $\begin{array}{c}161.74 \pm 31.28 \\
160 \\
110 / 220\end{array}$ & $<0.001$ \\
\hline $\begin{array}{l}\text { Ratio between the averages of systolic arterial pressure } \\
\text { (after/before) }\end{array}$ & $\begin{array}{c}\text { Average } \pm \text { SD } \\
\text { Median } \\
\text { Min. / Max. }\end{array}$ & $\begin{array}{c}0.82 \pm 0.21 \\
0.85 \\
0.00 / 1.00\end{array}$ & $\begin{array}{c}1.14 \pm 0.13 \\
1.10 \\
0.96 / 1.42\end{array}$ & $<0.001$ \\
\hline Total work throughout the test (Joule) & $\begin{array}{c}\text { Average } \pm \text { SD } \\
\text { Median } \\
\text { Min. / Max. }\end{array}$ & $\begin{array}{c}1443.50 \pm 1430.16 \\
864.0 \\
30 / 5739\end{array}$ & $\begin{array}{c}2495.22 \pm 1659.29 \\
2150.5 \\
237 / 7308\end{array}$ & $<0.001$ \\
\hline Average work per series of 30 repetitions (Joule) & $\begin{array}{c}\text { Average } \pm \text { SD } \\
\text { Median } \\
\text { Min. / Max. }\end{array}$ & $\begin{array}{c}263.73 \pm 169.05 \\
236.79 \\
15.00 / 704.20\end{array}$ & $\begin{array}{c}317.36 \pm 195.33 \\
256.56 \\
26.33 / 812.00\end{array}$ & 0.022 \\
\hline Average work per repetition (Joule) & $\begin{array}{c}\text { Average } \pm \text { SD } \\
\text { Median } \\
\text { Min. / Max. }\end{array}$ & $\begin{array}{c}8.79 \pm 5.64 \\
7.89 \\
0.50 / 23.47\end{array}$ & $\begin{array}{c}10.58 \pm 6.51 \\
8.55 \\
0.88 / 27.07\end{array}$ & 0.022 \\
\hline Peak Torque (Newton) & $\begin{array}{c}\text { Average } \pm \text { SD } \\
\text { Median } \\
\text { Min. / Max. }\end{array}$ & $\begin{array}{c}14.60 \pm 7.18 \\
13.53 \\
2.50 / 33.80\end{array}$ & $\begin{array}{l}16.53 \pm 8.01 \\
13.78 \\
3.89 / 35.11\end{array}$ & 0.019 \\
\hline
\end{tabular}

mum walking distance, but only the first group achieved a significant increase for all parameters studied; the authors concluded that surgery had the best results for increasing muscular performance (maximum performance, electrical efficacy, and fatiguability level) for patients with intermittent claudication..$^{22}$

However, there are clear differences between the musculature of the upper and lower limbs. Over the course of human evolution, the upper limbs have become specialized in performing movements that are finer and more precise than those of the lower limbs, thereby coming to present lesser but more specialized muscle mass that has lower blood support needs. The rich network of collateral circulation and lower demand for blood support make the symptoms of obstructive arterial disease less evident and more heterogeneous.?

Isokinetic dynamometers are electromechanical devices coupled to microcomputers that generate a resistance equal and opposite to the force exerted by the patient's musculature when the movement is made at a predetermined constant angular velocity. These devices allow objective and dynamic evaluation of muscle performance in specific muscle groups. ${ }^{16}$
To facilitate study and analysis, we decided to select only patients with SAOD. The choice was made via a protocol that allowed specific study to be made of the desired parameters of the muscle activity of the flexor and extensor groups of the elbow.

The obstruction of the subclavian artery often takes place at its origin, as was observed in all of our cases. Thus, one concern resulting from performing exercises of the upper limb would be the triggering of subclavian steal symptoms. ${ }^{23}$ This was not, however, observed in any of our cases.

The presence of SAOD is considered to be a risk factor for heart disease, ${ }^{24,25,26}$ and debilitating physical exertion may cause severe consequences. In evaluating heart rate by continuous monitoring of all the patients, we observed that none of them reached rates close to their maximum cardiovascular capacity, and no alteration in the electrical activity of the heart was seen.

Because the test is done selectively for a specific articular movement, it has low cardiovascular impact. ${ }^{21}$ This allows us to conclude that the test is safe from the point of view of heart exertion. No cases of test interruption because of clinical or electrocardiographic cardiac alteration were recorded in this series. 
In addition, this type of approach offers control of the movement in relation to the angular velocity. It allows recording of the torque produced during the whole amplitude of the movement, as well as identification of regions of strength or weakness within the amplitude of the movement. The tests can be repeated indefinitely with the immediate obtaining of results. The data can be stored on magnetic media for later use, especially for studies of patients' sequential evolution.

We initially sought to compare the limbs without arterial disease in the two groups to determine whether arms with SAOD (group 1) interfered in the functional performance of the contralateral limb (without arterial disease). We verified that there was no significant difference in the muscle performance between the normal limbs. Therefore, we could move on to analyze the test results between the members of group 1 .

Both upper limbs were tested until they reached their maximum limit, ie, the moment when the degree of pain or fatigue started to impede the continuation of the test, or when the maximum number of repetitions (270) was reached. This maximum number was set via a prior pilot study and had been found to be the most appropriate limit for the analysis of muscle function in the manner desired. This number of repetitions proved to be optimal, because the healthy limbs completed the test, while the diseased ones remained below this number. If the number of repetitions had been fewer, it would have been insufficient to provoke symptoms in cases with lower ischemic limitations.

The analysis of the maximum number of repetitions allowed the identification of a significant difference between the limbs with and without SAOD. There was a correlation with the degree of limitation reported by the patient, although we observed a significant variation in the number of repetitions among the limbs with SAOD.

The behavior of the systolic arterial pressure in each upper limb before and after the test was similar to what has been observed in lower limbs submitted to physical exercise. 27 We observed that the systolic pressure ratio tended to fall in limbs with SAOD and rise in normal limbs in a similar manner to what occurs in lower limbs with intermittent claudication. Although we consider this to be important data for clinical diagnosis, neither arterial pressure recorded while resting, nor the degree of fall in systolic arterial pressure had a direct relationship with the restriction in the number of repetitions or work achieved by the limb. In lower limbs with intermittent claudication undergoing conservative treatment with physical activity, we have often observed an increase in the maximum walking distances without any increase in the absolute arterial pressure of the limb or alteration in the ankle brachial index.
The differences in systolic arterial blood pressure were used as a first estimate of the degree of limitation to perfusion caused by arterial obstruction as well as the changes caused by the test. Although these measurements were considered valuable, they are limited in many clinical situations. On the basis of previous experience with lower limbs, absolute Doppler measurements alone do not necessarily correlate with clinical limitations and are not raised when patients increase their maximum walking distance. $^{28}$

Analysis of the maximum number of repetitions allowed identification of a significant difference between the limbs with and without SAOD .

While Isokinetic dynamometry is commonly used to evaluate strength, it also can be utilized as a resistance test. $^{29-33}$

Peak torque is considered to be the most important isokinetic parameter for evaluating muscular strength. ${ }^{32}$ It can be used for finding any early impairment in muscular performance of the tested limbs as well as for measurement of the level of strength achieved for both limbs,

Total work was analyzed as a complementary parameter for the muscular strength, offering data about work done by the muscular group during the whole test, and in this case, showing different levels of the patients' exercise resistance between the two groups. Gerdle, in 1987, considered it the most sensitive parameter for evaluating muscular fatigue. ${ }^{34}$

Data recorded by the dynamometer also showed lower values in peak torque and total work for the ischemic limb. For these parameters, the lower performance of limbs with SAOD in comparison to normal limbs can be objectively attributed to ischemia. These data allowed the degree of muscle performance during the test to be detailed. Some patients began the test with greater effort that subsequently diminished, while others maintained a constant level throughout the test. Patients probably develop different mechanisms to overcome the limitation caused by their SAOD.

In this report, we have presented a new noninvasive test that allows an objective and detailed evaluation of muscle function in patients with arterial disease of the upper limbs. This noninvasive test will allow patients with functional ischemia in the upper limbs to be evaluated not only in terms of the presence of the obstruction, but also in terms of identifying and quantifying the functional limitation caused by this disease. Thus, we can classify the patient according to the degree of functional limitation and pattern of muscle performance. Such classification will facilitate therapeutic decision-making and long-term follow-up. A new approach has been opened up, thereby creating a new field of research for arterial disease. 
In practical terms related to patients with conservative management, we will be able to follow up the long-term results of drug or exercise therapy as well as to propose interventions in the event of a poor response to therapy, decrease in muscle performance, or occurrence of a significant limitation. Regarding patients undergoing revascularization, we will be able to estimate the increase in muscle performance and follow up the clinical success. If thrombosis of the angioplasty or graft were to occur, we would be able to estimate the degree of worsening in terms of functional limitation, and thus decide more accurately on the necessity for further intervention.

\section{RESUMO}

Nakano L, Wolosker N, Rosoki RA, Muraco Netto B, Puech-Leão P. Avaliação objetiva da isquemia de membros superiores: uso do dinamômetro isocinético. Clinics. 2006;61(3):189-96.

OBJETIVO: O objetivo deste trabalho é apresentar um método para a avaliação da limitação funcional causada por doença arterial oclusiva de artéria subclávia: o teste de esforço utilizando o dinamômetro isocinético.

MÉTODO: Pacientes com trombose unilateral de artéria subclávia foram selecionados, reunindo 23 pacientes no Grupo com doença arterial oclusiva de artéria subclávia. Sete pacientes com idade semelhante, sem doença arterial em membros superiores foram incluídos, formando o grupo controle. Para a realização do teste, utilizou-se o dinamômetro isocinético CYBEX® 6000. O cotovelo foi testado em séries consecutivas de 30 repetições do movimento de extensão e flexão, até que se atingisse o máximo de 270 repetições ( 9 séries), ou até que se alcançasse o limite do membro testado.

RESULTADO: Inicialmente comparou-se todos os membros sem doença arterial dos dois grupos, para analisar se apresentavam desempenho semelhante. Não houve diferen- ça estatística entre os grupos em relação a todos os parâmetros estudados. Comparou-se então, os dois membros de cada paciente do Grupo doença arterial oclusiva de artéria subclávia. Em todos os parâmetros analisados, os membros com doença arterial oclusiva de artéria subclávia apresentaram diferença estatística $(\mathrm{p}<0.05)$ em relação aos membros controle, o que foi objetivamente atribuído à isquemia. (Foram registrados diferentes graus de limitação entre os paciente, o que permite estimar objetivamente o grau de limitação causado pela isquemia causada pela oclusão da subclávia)

CONCLUSÃO: Este teste de esforço permite que pacientes com isquemia de membros superiores sejam avaliados e estratificados, conforme o grau de sua limitação funcional, o que facilitará a escolha da melhor terapêutica para cada caso e a obtenção de parâmetros para comparação do resultado de diferentes tratamentos e para o seguimento clínico em longo prazo.

UNITERMOS: Isquemia. Extremidade Superior/irrigação sangüínea. Teste de esforço/instrumentação. Claudicação intermitente. Pressão arterial. Síndrome do roubo subclávio.

\section{REFERENCES}

1. Berguer R, Morasch MD, Kline RA, Kazmers A, Friedland MS. Cervical reconstruction of the supra-aortic trunks: a 16-year experience. J Vasc Surg. 1999;29:239-46.

2. Mesh CL, McCarthy WJ, Pearce WH, Flinn WR, Shireman PK, Yao JS Upper extremity bypass grafting. A 15 -year experience. Arch Surg. 1993;128:795-801.

3. Queral LA, Criado FJ. The treatment of focal aortic arch branch lesions with Palmaz stents. J Vasc Surg. 1996;23:368-75.

4. Fields WS, Lemak NA. Joint Study of Extracranial Arterial Occlusion. VII. Subclavian steal - a review of 168 cases. JAMA. 1972;222:113943.
5. Johnston KW. Neurovascular conditions involving the upper extremity. In: Rutherford RB, editor. Vascular Surgery. 4th ed. Philadelphia, USA: WB Saunders; 1995. p. 913-7.

6. Rapp JH, Reilly LM, Goldstone J, Krupsky WC, Ehremfeld WK, Stoney RJ. Ischemia of the upper extremity: Significance of proximal arterial disease. Am J Surg. 1986;152:122-6.

7. Williams SJ 2nd. Chronic upper extremity ischemia: current concepts in management. Surg Clin North Am. 1986;66:355-75.

8. Harris RB, Andros G, Dulawa LB, Oblath RW, Salles-Cunha SX, Apyan R. Large vessel occlusive disease in symptomatic upper extremity. Arch Surg. 1984;119:1277-82. 
9. Gosselin C, Walker PM. Subclavian Steal Syndrome: Existence, Clinical Features, Diagnosis and Management. Sem Vasc Surg. 1996;9:93-7.

10. Ackermann H, Diener HC, Seboldt H, Huth C. Ultrasonographic followup of subclavian stenosis and occlusion: Natural history and surgical treatment. Stroke. 1988;19:431-5.

11. Welling RE, Cranley JJ, Krause RJ, Hafner CD. Obliterative arterial disease of the upper extremity. Arch Surg. 1981;116:1593-96.

12. Ouriel K. Noninvasive diagnosis of upper extremity vascular disease. Sem Vasc Surg .1998;11(2):54-9.

13. Baxter BT, Blackburn D, Payne K, Pearce WH, Yao JS. Noninvasive evaluation of the upper extremity. Surg Clin North Am. 1990;70:87-97.

14. Edwards JM, Porter JM. Upper extremity arterial disease: etiological considerations and differential diagnosis. Sem Vasc Surg. 1998;11:60-6.

15. Edwards WH. Vertebral artery reconstruction: indications and techniques. Sem Vasc Surg. 1996;9:105-10.

16. Gardner AW, Skinner JS, Smith LK. Reliability of testing the knee extensors and flexors in healthy adult women using a Cybex II isokinetic Dynamometer. J Orthop Sports Phys Ther. 1991;14:37-47.

17. Wolosker N, Rosoky RA, Nakano L, Basyches M, Puech-Leao P. Predictive value of the ankle-brachial index in the evaluation of intermittent claudication. Rev Hosp Clin Fac Med Sao Paulo. 2000;55:61-4.

18. Gardner AW, Skinner JS, Smith LK. Effects of handrail support on claudication and hemodynamic responses to single-stage and progressive treadmill protocols in peripheral vascular occlusive disease. Am J Cardiol. 1991;68:99-105.

19. Hiatt WR, Hirsch AT, Regensteiner JG, Brass EP. Clinical trials for claudication. Assessment of exercise performance, functional status and clinical end points. Circulation. 1995;92:614-21.

20. Wolosker N, Nakano L, Rosoky RA, Puech-Leao P.Evaluation of walking capacity over time in 500 patients with intermittent claudication who underwent clinical treatment. Arch Intern Med. 2003;163:2296300 .

21. Gerdle B, Hedberg B, Angquist KA, Fugl-Meyer AR. Isokinetic strength and endurance in peripheral arterial insufficiency with intermittent claudication. Scand J Rehabil Med. 1986;18:9-15.
22. Hedberg B, Langstrom M, Angquist KA, Fugl-Meyer AR. Isokinetic plantar flexor performance and fatiguability in peripheral arterial insufficiency. Effects of training vs. vascular surgery. Acta Chir Scand. 1988;154:363-9.

23. Webster MW, Downs L, Yonas H, Makaroun MS, Steed DL. The effect of arm exercise on regional cerebral blood flow in the subclavian steal syndrome. Am J Surg. 1994;168:91-3.

24. Vogt DP, Hertzer NR, O’Hara PJ, Beven EG. Brachiocephalic artery reconstruction. Ann Surg. 1982;196:541-52.

25. Brewster DC, Moncure AC, Darling RC, Ambrosino JJ, Abbott WM. Innominate artery lesions: problems encountered and lessons learned. J Vasc Surg 1985;2(1):99-112.

26. Evans WE, Williams TE, Hayes JP. Aortobrachiocephalic reconstruction. Am J Surg. 1988;156:100-2.

27. Carter SA: Response of ankle systolic pressure to leg exercise in mild or questionable arterial disease. N Engl J Med. 1972;287:578-82.

28. Jonason T, Ringqvist I. Changes in peripheral blood pressures after five years of follow up in nonoperated patients with intermittent claudication. Acta Med Scand. 1986;220:127-32.

29. Patton RW, Hinson MM, Arnold BR, Lessard B. Fatigue curves of isokinetic contractions. Arch Phys Med Rehabil. 1979;59:507-9.

30. Burdett RG, Swearinger JV. Reliability of isokinetic muscle endurance tests. J Orthop Sports Phys Ther. 1987;8:484-8.

31. Montgomery LC, Douglas LW, Deuster PA. Reliability of an isokinetic test of muscle strength and endurance. J Orthop Sports Phys Ther. 1989;11:315-22

32. Kannus P. Isokinetic evaluation of muscular performance: implications for muscle testing and rehabilitation. Int J Sports Med. 1994;15 Suppl 1:S11-8.

33. Thorstensson A, Karlsson J. Fatiguability and fibre composition of human skeletal muscle. Acta Physiol Scand. 1976;98:318-22.

34. Gerdle B, Langström M. Repeated isokinetic plantar flexions at different angular velocities. Acta Physiol Scand. 1987;130:495-500. 